\title{
Case-report: EBV driven lymphoproliferative disorder associated with Ruxolitinib
}

\author{
Róbert Pálmason ${ }^{1,3^{*}}$, Ola Lindén ${ }^{2,3}$ and Johan Richter ${ }^{1,3}$
}

\begin{abstract}
Background: Ruxolitinib, a novel inhibitor of Janus kinases 1 and 2, was recently approved for the treatment of myelofibrosis but, recently, attention has been drawn to potential side effects and especially opportunistic infections and virus reactivations. EBV reactivation has not previously been reported to occur in association with Ruxolitinib.

Case presentation: We report a case of a 57 year old female with post-polycythemic myelofibrosis who was treated with Ruxolitinib. Approximately 9 weeks later she presented with a rapidly fatal, suspected EBV driven lymphoproliferative disorder in the CNS.

Conclusions: Our report further underlines that patients treated with Ruxolitinib should be monitored closely for reactivations of opportunistic pathogens and viral infections.
\end{abstract}

Keywords: Ruxolitinib, Side-effects, EBV, Lymphoma, Lymphoproliferative disorder

\section{Background}

Ruxolitinib was recently approved for the treatment of myelofibrosis and numerous studies are underway examining its effect in other myeloproliferative neoplasms. This novel inhibitor of Janus kinases 1 and 2 has shown promising effects in reducing constitutional symptoms and splenomegaly in patients with myelofibrosis and more recently was also shown to increase overall survival $[1,2]$. Recently, attention has been drawn to potential side effects of Ruxolitinib and especially opportunistic infections and viral reactivations [3-9]. Here we report on a patient with a rapidly fatal, suspected EBV driven lymphoproliferative disorder in the CNS developing shortly after administration of Ruxolitinb.

\section{Case presentation}

A 57 year old Caucasian woman with a history of Polycythemia vera (PV) presented to our institution with progressive debilitating constitutional symptoms. She had received her diagnosis 25 years ago and underwent splenectomy 15 years earlier after a splenic vein thrombosis. Three years earlier she was diagnosed with focal segmental glomerulosclerosis (FSGS) with a progressive renal failure,

\footnotetext{
* Correspondence: robert.palmason@med.lu.se

'Department of Hematology and vascular disorders, Skåne University Hospital, Lund, Sweden

${ }^{3}$ Lund University, Lund, Sweden

Full list of author information is available at the end of the article
}

presently with an estimated glomerular filtration rate according to plasma Iohexol clearance of $43 \mathrm{~mL} / \mathrm{min} /$ $1,73 \mathrm{~m}^{2}$ and a nephrotic syndrome. Earlier, her FSGS was treated with Prednisolone, Tacrolimus and Adrenocorticotrophic hormone (ACTH) but currently she was not under active treatment. Throughout the years she received numerous treatment modalities for her PV including phlebotomy, 32P, Hydroxyurea and Anagrelide. At the time of presentation progressive debilitating constitutional symptoms in the form of fatigue, low grade fever and weight loss had developed. A diagnosis of post-polycythemic myelofibrosis was made on a bone marrow biopsy. She was treated with pegylated interferon alfa-2a but shortly after her second injection developed severe headache that required hospital admission. CT and MRI of the brain were normal. Lumbar puncture was not performed. Progressive proteinuria was noted and the patient was treated with Prednisolone $30 \mathrm{mg}$ daily. The pegylated interferon alfa $2 \mathrm{a}$ treatment was stopped and her headache gradually disappeared. Three weeks later, treatment with Ruxolitinib was started at a dose of $10 \mathrm{mg}$ bid and the patient had a partial resolution of symptoms. Approximately 9 weeks after the beginning of Ruxolitinib therapy the patient was admitted, now for three grand mal seizures.

On diffusion-weighted MRI scan of the brain there was a $2 \mathrm{~cm}$ ring lesion in the right temporal lobe with restricted diffusion and surrounding edema (Fig. 1). The 


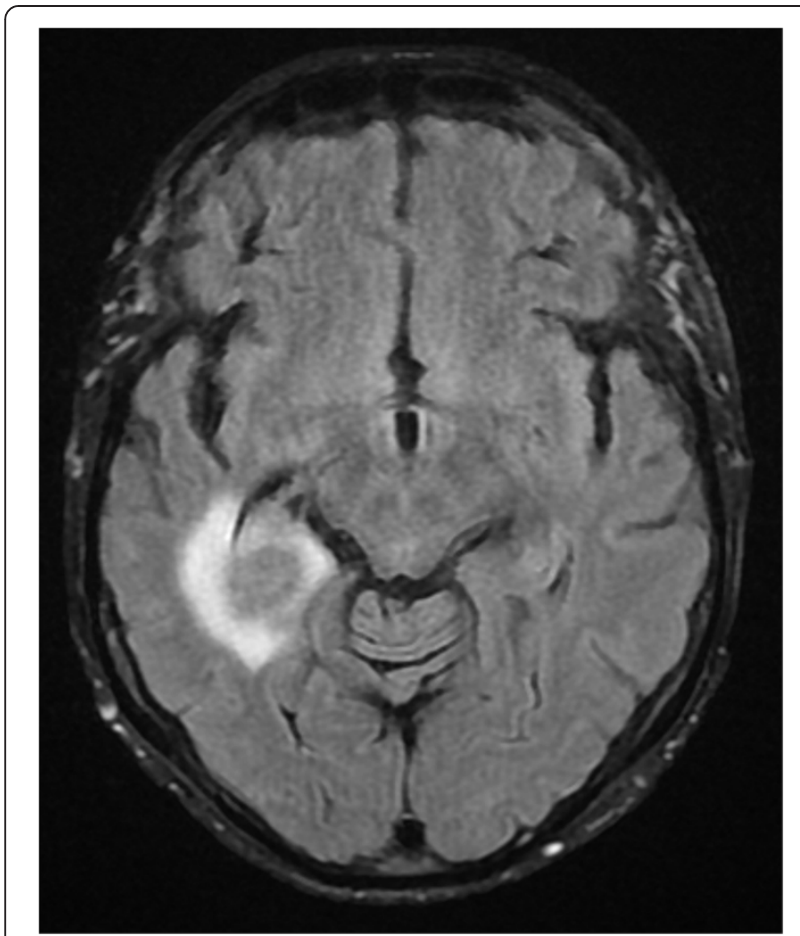

Fig. $1 \mathrm{MRl}$ of the head showing ring enhanced lesion in the right temporal lobe with surrounding edema at the time of diagnosis

radiographic appearance was highly suspicious of a CNS lymphoma. Retrospective examination of MRI taken 11 weeks earlier showed no signs of tumor. PET-CT showed 18 F-FDG lesion uptake but no signs of disseminated disease. Cerebrospinal fluid (CSF) analysis showed marginally elevated mononuclear cells $\left(11 \times 10^{6} / \mathrm{mL}\right)$ but flow cytometry analysis and cytology of the CSF were negative. Bacterial and mycobacterial cultures were negative. However, PCR analysis of CSF was positive for Epstein-Barr virus with 100000 copies $/ \mathrm{mL}$ while only mildly positive in serum with $<250$ copies $/ \mathrm{mL}$. PCR for JC, CMV, HHV6, HSV and VZV virus in the CSF were negative. A diagnosis of CNS lymphoproliferative disorder was suggested and Ruxolitinib was stopped. No biopsy was made. Because of co-morbidities the patient was deemed not to be a candidate for aggressive chemotherapy and palliative CNS radiotherapy, 24 Gy in 12 daily fractions, was commenced and she was treated concurrently with Rituximab and Temozolamide. Her condition worsened quickly thereafter and a repeated MRI showed a progressive disease (Fig. 2), now with multiple metastases in the brain and a midline shift. The patient passed away 5 weeks after her diagnosis. An autopsy was not performed.

\section{Discussion}

In the earlier studies on the efficacy and safety of Ruxolitinib the major reported side effects were dose-related

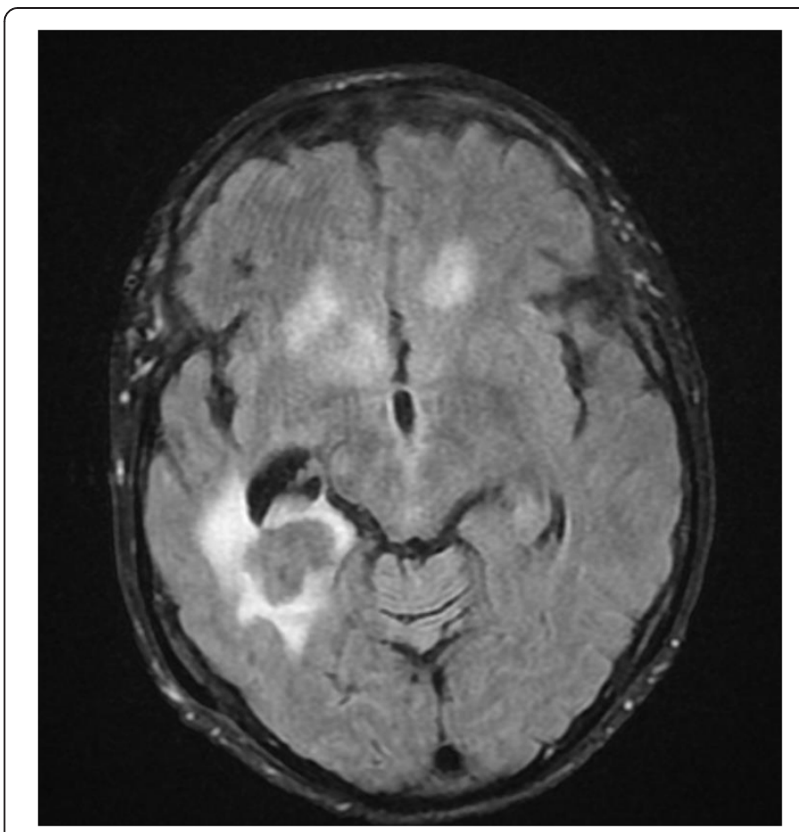

Fig. $2 \mathrm{MRI}$ at time of progression 4 weeks later

hematologic toxicity with anemia, neutropenia and thrombocytopenia. Herpes Zoster reactivation was described and awareness for this is recommended as is screening for latent tuberculosis [2]. Recently, published reports have described viral reactivations of Hepatitis $B[3,5]$ toxoplasma chorioretinitis [4], cryptococcus neoformans [8], mucormycosis, herpes simplex [6] and pneumocystis jiroveci [9] associated with the use of Ruxolitinib.

Studies have been conducted where the immunosuppressive effects of Ruxolitinib have been evaluated. A phase $1 / 2$ study showed a marked decrease in proinflammatory cytokines in patients receiving Ruxolitinib [10] which likely plays a role in the favorable effect of the drug in reducing myelofibrosis related symptoms. A pre-clinical model showed reduced dendritic cell function after the administration of Ruxolitinib resulting in an impaired $\mathrm{CD} 4^{+}$and $\mathrm{CD} 8^{+} \mathrm{T}$ cell priming in vitro and in vivo [11]. Another study in patients receiving Ruxolitinib showed a marked and long-lasting decrease in regulatory $\mathrm{T}$-cells, which are known to have a protective role against viral pathogens [12].

To our knowledge this is the first case describing EBV driven suspected lymphoproliferative disorder during Ruxolitinib therapy. Although no biopsy was made, the radiographic finding of a cerebral ring enhanced lesion with an avid 18 F-FDG uptake in a patient with a high copy number of EBV in the CSF and the virtual absence of EBV transcripts in serum, makes the suggested diagnosis highly plausible. Other differential diagnosis of cerebral ring enhanced lesions including metastases, abscesses or tuberculosis seem less likely in this case. 
Ruxolitinib may have, in conjunction with other immunosuppressive factors such as asplenia and long term steroid treatment, led to EBV reactivation in this patient who was seropositive for EBV (IgG but not IgM) before treatment initiation. The fact that the patient did undergo an MRI of the brain, that was normal, only 3 weeks prior to initiation of Ruxolitinib therapy strongly suggests that the disorder developed after the beginning of Ruxolitinib therapy.

\section{Conclusions}

We describe a patient with post-polycythemic myelofibrosis who was treated with Ruxolitinib. Nine weeks later she presented with a rapidly fatal EBV driven suspected CNS lymphoproliferative disorder which was refractory to radiotherapy, Rituximab and Temozolamid. Our report further underlines that patients treated with Ruxolitinib should be monitored for reactivation of opportunistic pathogens and viral infections, as recently suggested [13].

\section{Consent}

Written informed consent was obtained from the relatives of our patient for publication of this Case report. A copy of the written consent is available for review by the Editor-in-Chief of this journal.

\section{Abbreviations}

18 F-FDG: 18 F-Fluorodeoxyglucose; ACTH: Adrenocorticotrophic hormone; CNS: Central nervous system; CSF: Cerebrospinal fluid; CT: Computed tomography; EBV: Epstein Barr virus; FSGS: Focal segmental glomerulosclerosis; MRI: Magnetic resonance imaging; PCR: Polymerase chain reaction; PET: Positron emission tomography.

\section{Competing interests}

The authors declare that they have no competing interests.

\section{Authors' contributions}

$\mathrm{RP}, \mathrm{OL}$ and JR wrote the manuscript and all authors read and approved the final manuscript.

\section{Author details}

${ }^{1}$ Department of Hematology and vascular disorders, Skåne University Hospital, Lund, Sweden. 'Department of Oncology, Skåne University Hospital, Lund, Sweden. ${ }^{3}$ Lund University, Lund, Sweden.

Received: 26 September 2014 Accepted: 12 May 2015

Published online: 11 July 2015

\section{References}

1. Verstovsek S, Mesa RA, Gotlib J, Levy RS, Gupta V, DiPersio JF, Catalano JV, Deininger MWN, Miller CB, Silver RT, Talpaz M, Winton EF, Harvey Jr. JH, Arcasoy MO, Hexner EO, Lyons RM, Paquette R, Rasa A, Vaddi K, Erickson-Viitanen S, Sun W, Sandor V, Kantarjian HM. Efficacy, safety and survival with ruxolitinib in patients with myelofibrosis: results of a median 2-year follow-up of COMFORT-I. Haematologica. 2013;98:1865-71.

2. Cervantes F, Vannucchi AM, Kiladjian J-J, Al-Ali HK, Sirulnik A, Stalbovskaya V, McQuitty M, Hunter DS, Levy RS, PAssamonti F, Barbui T, Barosi G, Harrison CN, Knoops L, Gisslinger H. Three-year efficacy, safety, and survival findings from COMFORT-II, a phase 3 study comparing ruxolitinib with best available therapy for myelofibrosis. Blood. 2013;122:4047-53.

3. Caocci G, Murgia F, Podda L, Solinas A, Atzeni S, La Nasa G. Reactivation of hepatitis $B$ virus infection following ruxolitinib treatment in a patient with myelofibrosis. Leukemia. 2014;28:225-7.
4. Goldberg RA, Reichel E, Oshry LJ. Bilateral toxoplasmosis retinitis associated with ruxolitinib. N Engl J Med. 2013;369:680-1.

5. Shen $\mathrm{C}-\mathrm{H}$, Hwang $\mathrm{C}-\mathrm{E}$, Chen $\mathrm{Y}-\mathrm{Y}$, Chen C-C: Hepatitis B virus reactivation associated with ruxolitinib. Ann Hematol 2013, e-pub ahead of print 31 october 2013; doi:10.1007/s00277-013-1936-5.

6. Tong LX, Jackson J, Kerstetter J, Worswick SD. Reactivation of herpes simplex virus infection in a patient undergoing ruxolitinib treatment. J Am Acad Dermatol. 2014;70:e59-60.

7. Wathes R, Moule S, Milojkovic D. Progressive multifocal leukoencephalopathy associated with ruxolitinib. N Engl J Med. 2013:369:197-8.

8. Wysham N, Sullivan D, Allada G. An opportunistic infection associated with ruxolitinib, a novel janus kinase 1,2 inhibitor. Chest. 2013;143:1478-9.

9. Lee SC, Feenstra J GP. Pneumocystis jiroveci pneumonitis complicating ruxolitinib therapy. BMJ Case Rep 2014, e-pub ahead print 2 july 2014; doi:10.1136/bcr-2014-204950.

10. Verstovsek S, Kantarjian H, Mesa RA, Pardanani AD, Cortes-Franco J, Thomas DA, Estrov Z, Fridman JS, Bradley EC, Erickson-Viitanen S, Vaddi K, Levy R, Tefferi A. Safety and efficacy of INCB018424, a JAK1 and JAK2 inhibitor, in myelofibrosis. N Engl J Med. 2010;363:1117-27.

11. Heine A, Held SAE, Daecke SN, Wallner S, Yajnanarayana SP, Kurts C, Wolf D, Brossart $P$. The JAK-inhibitor ruxolitinib impairs dendritic cell function in vitro and in vivo. Blood. 2013;122:1192-202.

12. Massa M, Rosti V, Campanelli R, Fois G, Barosi G. Rapid and long-lasting decrease of T-regulatory cells in patients with myelofibrosis treated with ruxolitinib. Leukemia. 2014;28:449-51.

13. Heine $A$, Brossart $P$, Wolf $D$. Ruxolitinib is a potent immunosuppressive compound: is it time for anti-infective prophylaxis? Blood. 2013;122:3843-4.

\section{Submit your next manuscript to BioMed Central and take full advantage of:}

- Convenient online submission

- Thorough peer review

- No space constraints or color figure charges

- Immediate publication on acceptance

- Inclusion in PubMed, CAS, Scopus and Google Scholar

- Research which is freely available for redistribution 